\title{
Clinical, haemodynamic, and antiarrhythmic effects of long term treatment with amiodarone of patients in heart failure
}

\author{
JOHN G F CLELAND, HENRY J DARGIE, IAIN N FINDLAY, JOHN T WILSON \\ From the Department of Cardiology, Western Infirmary, Glasgow
}

SUMMARY Twenty two patients with heart failure were studied in a double blind crossover trial to compare amiodarone $(200 \mathrm{mg} /$ day $)$ with placebo. Each agent was given for three months. Extrasystoles and complex ventricular arrhythmias were common during ambulatory electrocardiographic monitoring and during exercise testing at entry to the study. Breathlessness and tiredness as assessed by visual analogue scores and duration of treadmill exercise did not become worse during amiodarone treatment. During the placebo and amiodarone phases of the study left ventricular ejection fraction and cardiac index determined by first pass radionuclide ventriculography were similar, both at rest and during upright bicycle exercise. Exercise induced ventricular tachycardia was abolished and simple and complex ventricular arrhythmias observed on 24 hour ambulatory monitoring were greatly diminished during amiodarone treatment. Three patients died, all suddenly, during the placebo phase. In two patients amiodarone was withdrawn after a further myocardial infarction in one and a worsening of symptoms of ventricular arrhythmia in the other.

In contrast with other antiarrhythmic agents amiodarone is effective in suppressing ventricular arrhythmias in heart failure without causing adverse haemodynamic effects. Because frequent ventricular arrhythmias are known to be associated with a poor prognosis in heart failure, these data suggest that amiodarone may improve the poor prognosis in patients with heart failure.

Most patients with chronic heart failure primarily caused by left ventricular dysfunction die suddenly, not from progressively worsening heart failure and pulmonary oedema ${ }^{1-3}$ but presumably from ventricular arrhythmias. Asymptomatic ventricular arrhythmias are often found on ambulatory electrocardiographic monitoring ${ }^{45}$ and several workers have noted an association between their occurrence and the poor prognosis of patients with heart failure. ${ }^{246}$ Thus there may be a place for antiarrhythmic treatment in patients with heart failure and ventricular arrhythmias. The negative inotropic effects of many antiarrhythmic agents ${ }^{7-9}$ could offset their antiarrhythmic effects. ${ }^{10}$ Moreover, class I antiarrhythmic agents have been ineffective in improving prognosis ${ }^{11}$ despite evidence that some

Requests for reprints to Dr John G F Cleland, Waller Department of Cardiology, St Mary's Hospital, London W2 1NY.

Accepted for publication 24 November 1986 can reduce the frequency of arrhythmias in patients with heart failure.

Amiodarone, a class III antiarrhythmic agent, has a unique electrophysiological mode of action ${ }^{12}$ and in addition is a powerful coronary and peripheral vasodilator. ${ }^{1314}$ Although amiodarone also has been found to have acute negative inotropic effects ${ }^{1516}$ when given in large intravenous doses, which may be due to a non-competitive adrenergic antagonism, this is less apparent during long term use. ${ }^{15}$

We know of no controlled studies on the long term effects of amiodarone in patients with heart failure. In the present study we have investigated the effects of medium term amiodarone treatment on symptoms, exercise performance, left ventricular function, and arrhythmia frequency in a double blind placebo controlled crossover trial.

\section{Patients and methods}

We recruited 22 patients ( 19 men) with heart failure, 
present for more than six months, into a double blind crossover study with treatment phases (amiodarone or placebo) lasting three months. Ten received amiodarone as the first treatment and 12 placebo. Both treatments were visually identical. The mean (SD) age of the patients was 56 (8) years, the median daily dose of frusemide was $120 \mathrm{mg}$ (range 40-200 mg), mean (SD) end diastolic left ventricular dimension $6.8(0.9) \mathrm{cm}$ (normal $<5.6 \mathrm{~cm}$ ), and mean (SD) fractional shortening $14.3(1.5) \%$ (normal $>28 \%$ ). All had stable heart failure; 10 were in New York Heart Association functional class III and 12 were in class II. Sixteen patients were taking digoxin (median daily dose $0.25 \mathrm{mg} /$ day, range $0.0625-0.375$ ), though all were in sinus rhythm. The diagnosis of congestive (dilated) cardiomyopathy in eight and ischaemic heart disease in 14 was established at cardiac catheterisation. Patients were selected because they had heart failure and not because they had serious symptomatic ventricular arrhythmias.

Ten patients were taking captopril, which had been started at least three months before entry to the study (mean 11.8 months, range 4-31 months). Seven others had been taking amiloride and one spironolactone for at least three months because hypokalaemia had developed while they were on diuretics. Amiodarone was adminstered in a dose of $200 \mathrm{mg}$ three times a day for seven days and $200 \mathrm{mg}$ once a day thereafter.

\section{SYMPTOMS}

Before the study and at the end of each treatment phase symptoms of breathlessness, tiredness, and ankle swelling were assessed by visual analogue scores.

\section{HEART RATE AND BLOOD PRESSURE}

Heart rate was counted from the apex beat and blood pressure was recorded in recumbent and standing positions with a Hawkesley Random-zero sphygmomanometer.

\section{ELECTROCARDIOGRAPHY AND EXERCISE TESTING}

Ambulatory electrocardiography was performed for 48 hours on a Medilog I system and analysed for isolated ventricular extrasystoles, complex ventricular extrasystoles (bigeminy or two or more consecutive beats), and ventricular tachycardia (three or more consecutive beats at $>120$ beats $/ \mathrm{min}$ ). Results are expressed as events per 24 hours. A 12 lead electrocardiogram was also performed at each visit. A treadmill exercise test was carried out according to a modified Bruce protocol. The test was symptom limited.
RADIONUCLIDE VENTRICULOGRAPHY

Radionuclide ventriculograms were obtained at rest and during upright bicycle exercise with a multicrystal gamma camera (Baird Atomic System 77) and a one inch thick parallel hole collimator. After the injection of $300 \mathrm{mBq}$ of technetium-99m counts were recorded at a framing interval of $40 \mathrm{~ms}$ (25 frames/s) with the patient resting. A static image was obtained for background correction and exercise was started at a workload of $25 \mathrm{~W}$, increasing by $25 \mathrm{~W}$ every three minutes until limited by symptoms. Images were acquired at peak exercise after a further injection of $500 \mathrm{mBq}$ of technetium-99m; counts were recorded at a framing interval of $20 \mathrm{~ms}$ (50 frames/s). All radionuclide ventriculograms were corrected for non-uniformity of field by a technetium-99m flood source and for image acquisition during exercise for radiation background from the previous acquisition. The studies were then viewed as serial one second images and frames that included the left ventricle were displayed. A zone of interest representing the left ventricle was defined and a histogram of counts against time was displayed. Because the left ventricular function of the study subjects was poor images of up to eight beats were often obtained before there was appreciable recirculation of radionuclide.

Left ventricular ejection fraction was calculated from the standard formula: end diastolic counts minus end systolic counts divided by end diastolic counts minus background. Background was determined by examining the histogram to identify those frames that occurred immediately before the appearance of the peaks and troughs that are typical of the

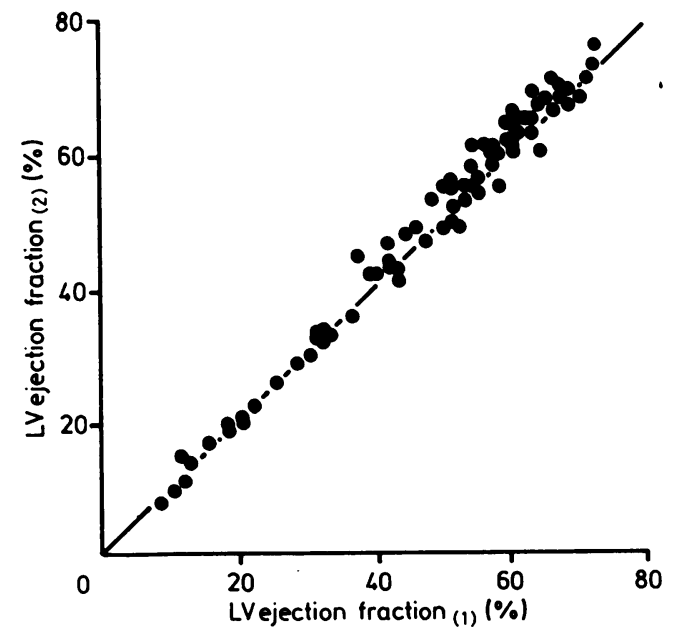

Fig 1 Intraobserver reproducibility of left ventricular ejection fraction $(i=100 ; r=0.99 ; y=0.98 x+0.4$; standard error of the regression $=2 \cdot 2 \%$ ). 


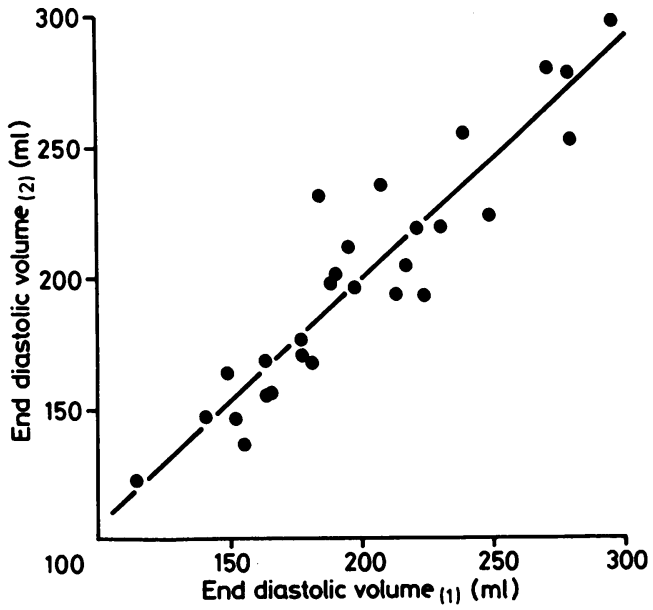

Fig 2 Intraobserver reproducibility of left ventricular end diastolic volume $(n=30 ; r=0.94 ; y=0.93 x+14$; standard error of the regression $=17 \mathrm{ml}$ ).

left ventricular counts. In our laboratory left ventricular ejection fraction measured by first pass radionuclide ventriculography correlates well with left ventricular ejection fraction measured by contrast angiography $(r=0 \cdot 86, n=38)$. The end diastolic volume was obtained by applying a $21 \%$ isocontour to the end diastolic image. The volume was calculated by the Sandler-Dodge area-length method and in 17 subjects it correlated well with the results of contrast angiography $(r=0.9$, standard error of the estimate $24 \mathrm{ml}$ ). Intraobserver reproducibility for left ventricular ejection fraction is $r=0.99$ (fig 1 ) and for end diastolic volume $r=$ 0.94 (fig 2).

\section{BIOCHEMICAL ANALYSIS}

Blood was taken at each visit for the measurement of serum urea, creatinine, digoxin, and electrolytes and also for plasma active renin concentration, ${ }^{17}$ angiotensin II, ${ }^{18}$ aldosterone, ${ }^{19}$ catecholamines, ${ }^{20}$ and for thyroid function at baseline and at the end of each treatment phase. Plasma amiodarone concentrations were measured 24 hours after the last dose of the drug. Pulmonary function tests were performed at baseline and at the end of each treatment phase. In addition, patients were assessed clinically at one, two, four, and eight weeks after each change of treatment.

STATISTICAL ANALYSIS

Order and period effects were excluded by comparing the differences between observations for the amiodarone and placebo phases of the two groups by means of two-sample $t$ tests; results for the amiodarone and placebo treatment phases were com- pared by Student's $t$ test with log transformation if appropriate. Where sequential observations were made analysis of variance was applied. Correlation coefficients were calculated by the least squares method for normally distributed data.

\section{Results}

\section{BASELINE}

At entry to the study six of the 22 patients recruited did not have an episode of ventricular tachycardia on 48 hour electrocardiographic monitoring and eight had fewer than 30 ventricular extrasystoles per hour. The median frequency of ventricular extrasystoles in 24 hours was 2487 per 24 hours and of episodes of ventricular tachycardia eight per 24 hours. During exercise all but one of the patients in whom asymptomatic ventricular tachycardia developed were limited by breathlessness or fatigue. Five other patients had episodes of self terminating ventricular tachycardia during exercise testing.

The radionuclide ejection fraction was $20(9) \%$ at rest and rose to $25(10) \%(p<0.05)$ on exercise. No patient was hypokalaemic on admission to the study $(3.8(0.3)(3.5-4.6) \mathrm{mmol} / \mathrm{l}$ (mean (SD) and range)).

\section{REPRODUCIBILITY OF RADIONUCLIDE DATA}

The reproducibility of left ventricular ejection fraction was tested by correlating baseline and placebo data; it was accurate for both rest and exercise studies (figs 3 and 4). Cardiac output during baseline and placebo periods was consistent at rest but less so during exercise (figs 3 and 4). This lack of consistency could not be entirely accounted for by biological variability because the peak exercise heart rates during the two tests were similar.

\section{DOUBLE BLIND STUDY \\ Symptoms}

Table 1 shows that visual analogue scores for breathlessness and ankle swelling were unaffected by amiodarone, whereas tiredness showed a statistically insignificant tendency to increase.

\section{Heart rate and blood pressure (table 1)}

Both supine and upright heart rate were significantly lower on amiodarone. After seven days of treatment these two variables were significantly lower on amiodarone than on placebo (fig 5). Systolic blood pressure, supine or erect, was unaltered by amiodarone treatment, though diastolic blood pressure in the supine position alone was lower during amiodarone treatment. No difference in the heart rate or blood pressure response to amiodarone was noted in patients treated with captopril. 
Table 1 Effect of amiodarone on clinical signs and on ventricular arrhythmias in patients in heart failure

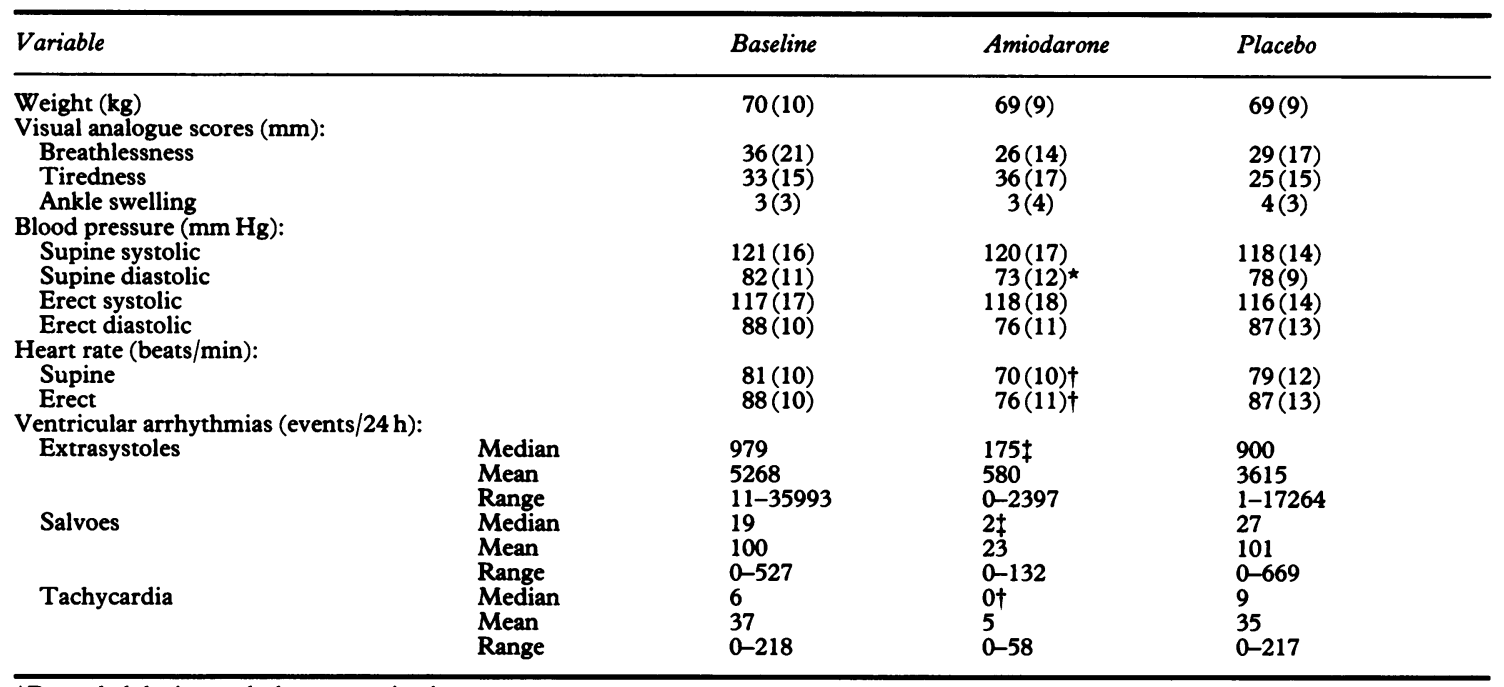

^Recorded during ambulatory monitoring.

Except were stated, values are means (SD).

${ }^{\star} p<0.05 ; \nmid p<0.01 ; \neq p<0.001$ compared with placebo values.
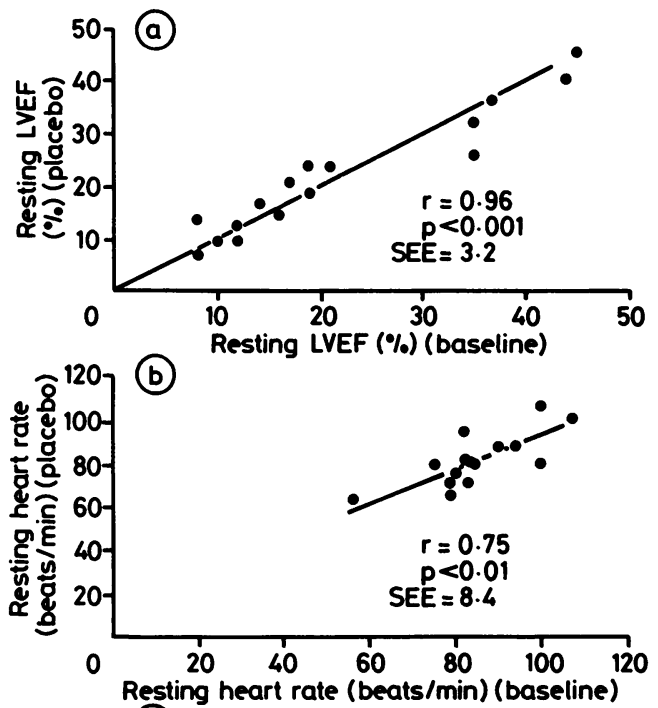

Ambulatory monitoring (table 1)

During amiodarone treatment there was a significant reduction in the frequency of isolated ventricular extrasystoles, complex ventricular extrasystoles, and ventricular tachycardia. There was no difference in arrhythmia control in patients with heart failure of differing aetiologies; but the groups may have been too small for any difference to become apparent.

\section{Exercise testing}

During the baseline phase six patients had one or more episodes of non-sustained ventricular tachycardia during their exercise test. Mean (SD) exercise duration was $10.5(4.2)$ minutes. There was no difference in mean exercise performance between the amiodarone and placebo phases of the trial $(12 \cdot 1(3.8)$ minutes on placebo and $12 \cdot 8(3.0)$ minutes on amiodarone); however, while on amiodarone two patients with ischaemic heart disease performed considerably better and no patient deteriorated. Peak exercise heart rate and systolic blood pressure were unaffected by treatment. In three patients non-sustained ventricular tachycardia developed during the placebo phase but not during treatment with amiodarone. All patients were limited by breathlessness or fatigue during this part of the study. No patient had chest discomfort, nor was any important ST depression seen.

\section{Radionuclide ventriculography (table 2)}

Fig 3 Correlation of resting values at baseline and during the placebo period. Correlation coefficient and standard error of the estimate ( $S E E$ ) for (a) resting left ventricular ejection fraction (LVEF), (b) resting heart rate, and (c) resting cardiac output.

The increase in exercise time on amiodarone approached statistical significance $(p<0.07)$; in a few patients measured during the amiodarone phase the exercise time was considerably longer than dur- 

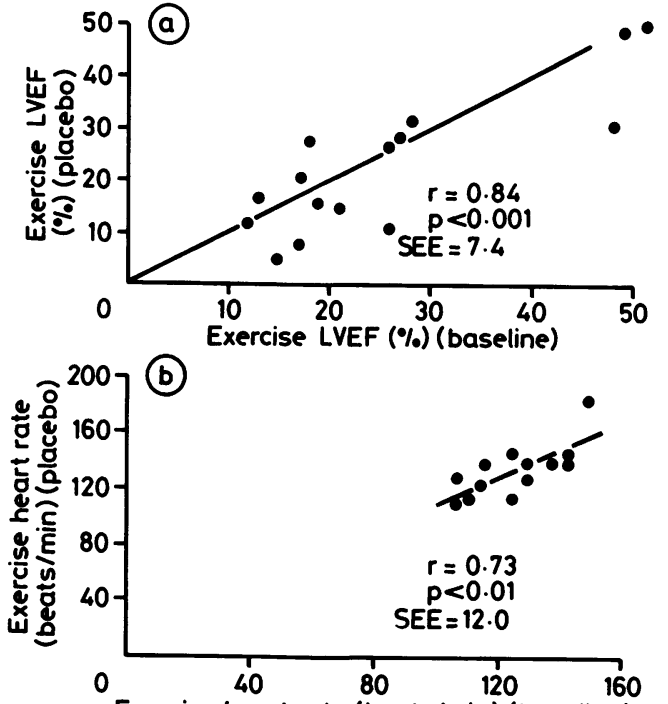

Exercise heart rate (beats/min) (baseline)

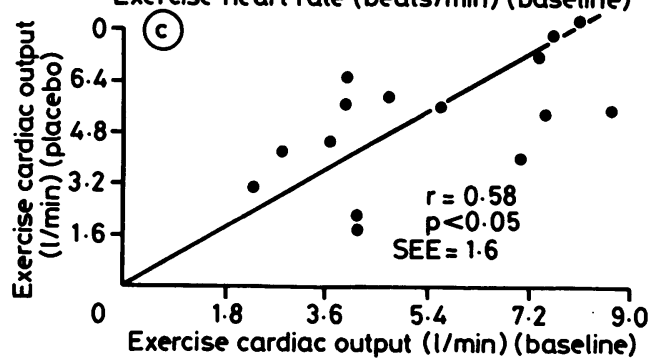

Fig 4 Correlation of values for variables measured during peak exercise at baseline and during the placebo period. Correlation coefficient and standard error of the estimate ( $S E E$ ) for (a) left ventricular ejection fraction, (b) heart rate, and (c) cardiac output. ing the placebo phase. Heart rate and blood pressure responses were similar during the placebo and amio- $c$. darone phases. Rest and exercise ejection fractions $\Rightarrow$ were not altered by amiodarone, nor was the $\frac{\rho}{?}$ increase in ejection fraction during exercise. We found no change in regional wall motion scores and $\overline{\bar{O}}$. no differences between patients with heart failure $\frac{\sqrt{\sigma}}{\sigma}$ caused by ischaemic heart disease and those in whom it had another cause. These groups may have been too small to show any real difference, however. $\overrightarrow{0}$

\section{Biochemistry (table 3)}

Concentrations of serum sodium, potassium, urea, and creatinine were unchanged. Plasma concen-cy trations of renin, angiotensin II, aldosterone, and $G$ noradrenaline were also unchanged during amio- $\dot{\vec{c}}$ darone treatment. Serum digoxin rose significantly on amiodarone. Digoxin dosage had been reduced $\mathrm{P}$ before the study to attain baseline concentrations at the lower end of the therapeutic range. A toxic concentration of serum digoxin was not found in any patient and the dose of digoxin was not altered dur- $\vec{\infty}$ ing the study. During amiodarone treatment serum. triiodothyronine concentrations fell while the concentration of serum thyroxine increased. Thyroid stimulating hormone concentrations also increased $\bar{\partial}$ during amiodarone treatment. Plasma amiodarone concentrations were negligible during the placebo $\frac{\mathbb{Q}}{2}$ phase of the study.

\section{2 lead electrocardiogram (fig 5)}

Heart rate was reduced and QTc prolonged after one and twelve weeks' treatment with amiodarone (fig 5). In most patients the PR interval did not increase.

Table 2 Haemodynamic variables (mean (SD)) measured during rest and exercise by radionuclide ventriculography

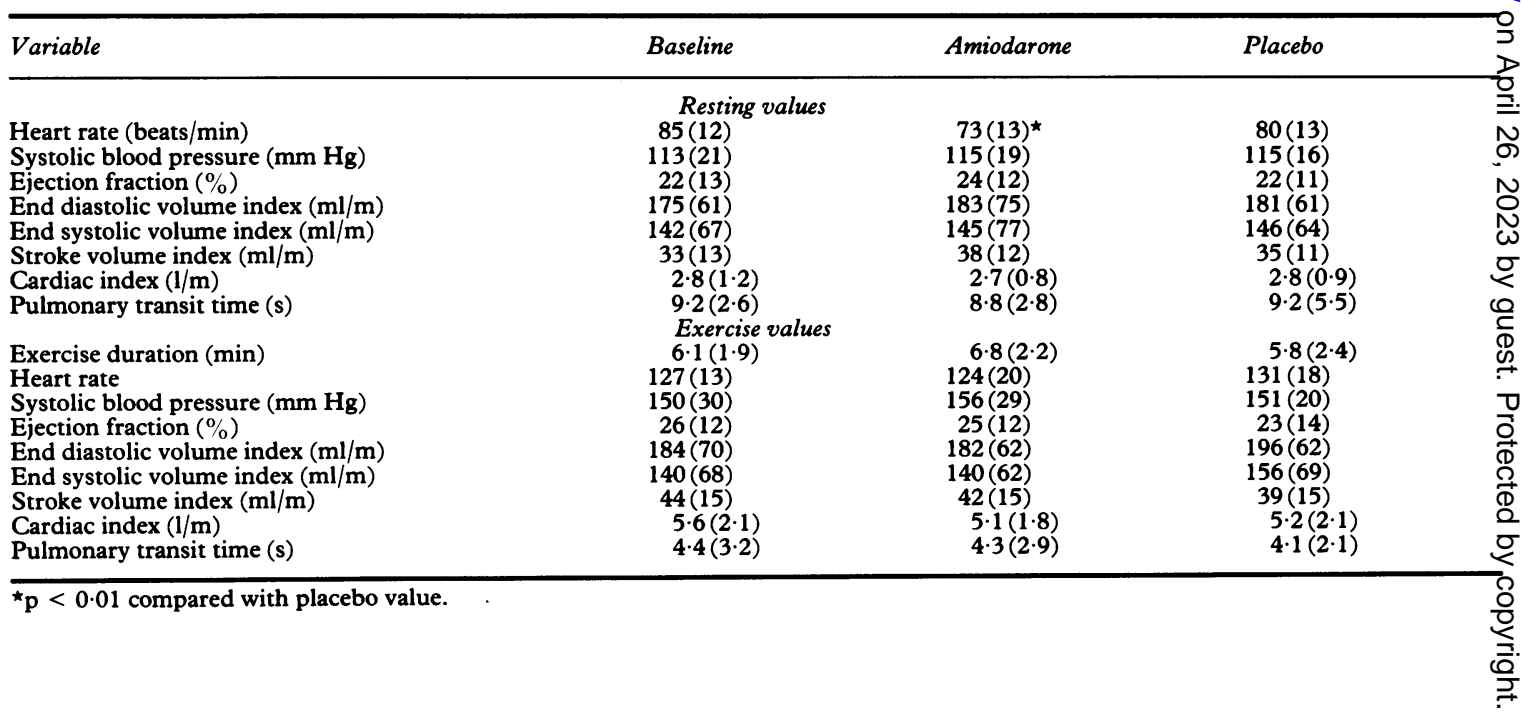


Table 3 Results of clinical biochemistry in patients in heart failure treated with amiodarone

\begin{tabular}{|c|c|c|c|}
\hline & Baseline & Amiodarone & Placebo \\
\hline $\begin{array}{l}\text { Serum digoxin }(\mathrm{nmol} / \mathrm{l}) \\
\text { Serum creatinine }(\mu \mathrm{mol} / \mathrm{l}) \\
\text { Serum sodium }(\mathrm{mmol} / \mathrm{l}) \\
\text { Serum potassium }(\mathrm{mmol} / \mathrm{l}) \\
\text { PARC }(\mu \mathrm{U} / \mathrm{ml}) \text { : }\end{array}$ & $\begin{array}{l}1 \cdot 1(0 \cdot 2) \\
106(14) \\
137(4) \\
3 \cdot 8(0 \cdot 4)\end{array}$ & $\begin{array}{l}1.9(0.4)^{\star} \\
103(13) \\
140(2) \\
3.9(0.3)\end{array}$ & $\begin{array}{l}1 \cdot 3(0 \cdot 2) \\
99(18) \\
139(3) \\
3 \cdot 8(0 \cdot 3)\end{array}$ \\
\hline $\begin{array}{l}\text { Median } \\
\text { Mean } \\
\text { Range }\end{array}$ & $\begin{array}{l}133 \\
558 \\
49-2565\end{array}$ & $\begin{array}{l}134 \\
332 \\
5-1867\end{array}$ & $\begin{array}{l}226 \\
578 \\
47-2768\end{array}$ \\
\hline $\begin{array}{l}\text { Plasma angiotensin II (pmol/1): } \\
\text { Median } \\
\text { Mean } \\
\text { Range }\end{array}$ & $\begin{array}{l}23 \\
35 \\
6-124\end{array}$ & $\begin{array}{l}18 \\
50 \\
2-111\end{array}$ & $\begin{array}{l}37 \\
50 \\
11-103\end{array}$ \\
\hline $\begin{array}{l}\text { Plasma aldosterone (pmol/l): } \\
\text { Median } \\
\text { Mean } \\
\text { Range } \\
\text { Plasma noradrenaline }(\mathrm{nmol} / \mathrm{l}) \\
\text { Plasma amiodarone }(\mathrm{mg} / \mathrm{l}) \\
\text { Range } \\
\text { Plasma desethylamiodarone }(\mathrm{mg} / \mathrm{l}) \\
\text { Range }\end{array}$ & $\begin{array}{l}430 \\
458 \\
102-1234 \\
4 \cdot 0(0 \cdot 6)\end{array}$ & $\begin{array}{l}294 \\
526 \\
174-1344 \\
2 \cdot 3(1 \cdot 6) \\
0 \cdot 8(0 \cdot 3) \\
0 \cdot 4-1 \cdot 3 \\
0 \cdot 7(0 \cdot 2) \\
0 \cdot 4(1 \cdot 3)\end{array}$ & $\begin{array}{l}382 \\
446 \\
83-1271 \\
3 \cdot 6(1 \cdot 5) \\
0 \\
0-0 \cdot 1 \\
0 \\
0-0 \cdot 1\end{array}$ \\
\hline
\end{tabular}

PARC, plasma active renin concentration.

Except where stated, values are mean (SD).

${ }^{\star} p<0.01$ compared with placebo values.

Table 4 Effects of amiodarone on pulmonary function tests, thyroid function, and 12 lead electrocardiography in patients in heart failure

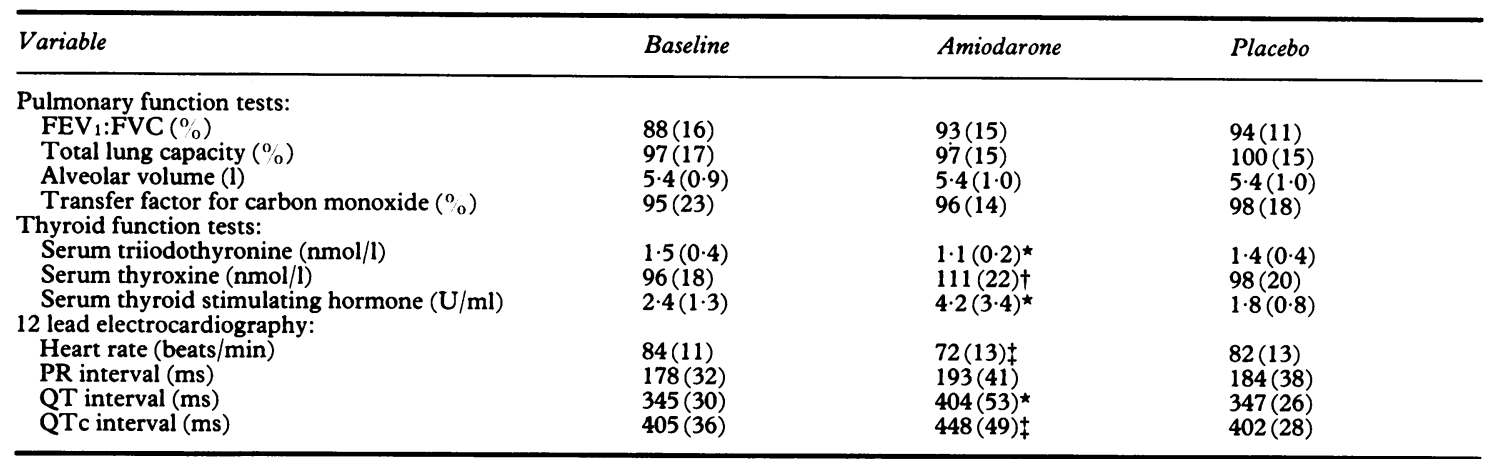

$\mathrm{FEV}_{1}: \mathrm{FVC}$, ratio of the forced expiratory volume in one second to the forced vital capacity.

${ }^{\star} \mathrm{p}<0.001 ; \mathrm{p}<0.05 ; \ddagger \mathrm{p}<0.01$ compared with placebo values.

Pulmonary function testing (table 4)

Tests of pulmonary function were unaltered by amiodarone.

\section{Clinical outcome}

Three patients died during the placebo phase of the study. All died suddenly with no prior worsening of symptoms. All three had both ventricular tachycardia on exercise testing and on $\mathbf{4 8}$ hour ambulatory monitoring. All three were taking digoxin; however, serum concentrations at the last clinic visit had been normal. One patient had a myocardial infarction during the amiodarone phase from which he made an uneventful recovery; this patient was withdrawn from the study. In one patient arrhythmias became much worse after a week on amiodarone and this patient was also withdrawn from the study. Subsequent treatment with flecainide caused severe heart failure; reintroduction of amiodarone at a lower dose ( $200 \mathrm{mg}$ once daily) has been partially effective in controlling his arrhythmias. In one patient episodes of 2:1 heart block developed on amiodarone and these were seen on ambulatory recording. Heart block resolved on placebo. Two patients with left bundle branch block showed no further deterioration in conduction on amiodarone. One patient developed limb paraesthesia without objective neurological signs; this disappeared spontaneously during the placebo phase of the study and subsequently has not recurred on a maintenance dose of $100 \mathrm{mg} /$ day. Good control of arrhythmias 


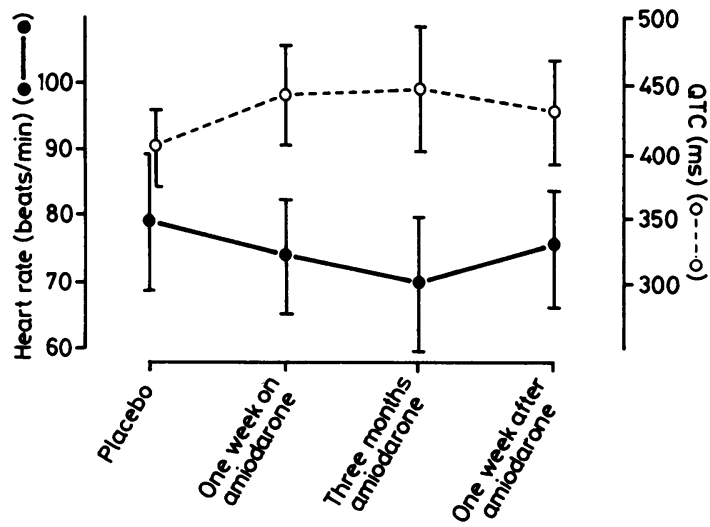

Fig 5 Sequential analysis (mean (SD)) of QTc and heart rate after one and 12 weeks of amiodarone and after one week of withdrawal of active treatment. Analysis of variance showed a significant $(p<0.01)$ change in heart rate and $Q T c$.

has continued. In each case the combination of captopril and amiodarone was well tolerated.

\section{Discussion}

Frequent ventricular extrasystoles are an ominous indicator of a poor prognosis in patients with chronic heart failure caused by left ventricular dysfunction. ${ }^{246}$ As yet there is no evidence that effective suppression of ventricular arrhythmias will prolong the life of a patient with heart failure. An appropriate, effective pharmacological agent is needed to investigate this possibility. Amiodarone is a class III antiarrhythmic agent with antiadrenergic activity $^{21}$ that also has a mild direct negative inotropic action that is offset by systemic vasodilatation. ${ }^{21}$ The electrophysiological effects of long term oral amiodarone include an increase in the effective refractory period of both atrial and ventricular myocardium and prolongation of atrial and, to a lesser extent, ventricular conduction times. ${ }^{22} 23$ Amiodarone reduces sinus node automaticity and thus contributes to a reduction in heart rate. ${ }^{22}$ The $\mathrm{A}-\mathrm{H}$ interval, and probably the $\mathrm{H}-\mathrm{V}$ interval ${ }^{22}{ }^{23}$ are also prolonged during oral dosing. Amiodarone's antiadrenergic activity is non-competitive, affects both alpha and beta receptor actions, and is probably mediated by a reduction in receptor density or uncoupling of receptors from adenylate cyclase activity. 212425

As far as we are aware, no controlled studies of the long term safety and efficacy of amiodarone in suppressing arrhythmias in patients with heart failure have been reported. In a short term study in patients with heart failure caused by Chagas's disease there was a mild transient fall in cardiac output and a rise $c$. in systemic vascular resistance and left ventricular $\vec{F}$ filling pressure on amiodarone treatment. ${ }^{26}$ Other $\stackrel{5}{\stackrel{9}{9}}$ short term studies in patients with coronary artery disease without heart failure have shown an increase $\frac{\bar{\sigma}}{\bar{c}}$. in cardiac output and fall in left ventricular end $\frac{\text { }}{2}$ diastolic pressure. ${ }^{27}$ Several studies have $\propto$ investigated the effects of long term amiodarone treatment in patients with severe left ventricular $\overrightarrow{0}$ dysfunction ${ }^{27-29}$; though these studies have suggested little or no deleterious effect of amiodarone $\vec{\omega}$ on left ventricular failure they have been uncontrolled and it was not clear that the patients were in heart failure.

In a double blind study we have demonstrated that amiodarone in a relatively low dose of $\omega$ $200 \mathrm{mg} /$ day can appreciably suppress ventricular arrhythmias, both during ambulatory monitoring and during treadmill exercise testing, without wor- $\frac{-}{z}$ sening symptoms in patients with heart failure of New York Heart Association grade II-III. Moreover, exercise performance and radionuclide ejec- $\infty$ tion fraction both at rest and during exercise were maintained. The negative inotropic effects of amiodarone might have been offset not only by systemic vasodilatation but also by coronary vasodilatation. In the presence of clinically inapparent reversible myocardial ischaemia, which may occur in dilated cardiomyopathy as well as in heart failure caused by ischaemic heart disease, the improvement in the myocardial supply:demand ratio by amiodarone may have maintained cardiac output and ejection fraction.

Resting heart rate was reduced and QTc was prolonged after only one week of amiodarone treatment, which suggests an early onset of electrophysiological action; these effects persisted throughout the $12 \%$ week treatment period. The corrected QT interval is $₹$ thought to correlate with plasma and myocardial 은 concentrations of amiodarone ${ }^{3031}$; however, the above effects occurred at relatively low concentrations of plasma amiodarone. In the eight patients for whom we have samples, plasma amiodarone con- of centrations were quite low on a maintenance dose of $N$ $200 \mathrm{mg} /$ day. $^{32}$ There were several possible expla- N nations for this. Firstly, patients may not have $\sigma$ reached steady state concentrations because the half 0 life for elimination of amiodarone is probably more $\mathbb{D}$ than one month. ${ }^{32}$ Amiodarone has a rapid initial $\stackrel{?}{-}$ distribution phase, ${ }^{32}$ and as samples were taken 24 hours after the last dose of amiodarone the measured concentration could have been appreciably lower than the maximum.

The reduction in heart rate on amiodarone was accompanied by a small increase in stroke volume, 
and because of this there was no change in resting or exercise cardiac output. A fall in systemic vascular resistance may have offset the slightly negative inotropic effect, but we did not demonstrate a reduction in sympathetic activity or renin-angiotensin activity-plasma concentrations of renin and noradrenaline were unchanged.

\section{DRUG INTERACTION}

The concentration of serum digoxin increased by $46 \%$ in this study and similar results have been obtained by others ${ }^{33}$; symptoms of digoxin toxicity did not occur. This may have been because of the low initial serum digoxin concentration. The rise in serum digoxin that we observed is unlikely to have contributed to the reduction in heart rate and the maintenance of left ventricular ejection fraction. Amiodarone has been used to treat digoxin induced arrhythmias. ${ }^{34}$ Amiodarone caused no further significant decline in blood pressure when it was used in conjunction with captopril. This combination seems well suited to the management of patients with heart failure who, as this study shows, commonly have serious arrhythmias. The combined effect of captopril and amiodarone in raising serum digoxin $^{35}$ should be noted, but otherwise we noted no other deleterious interaction.

\section{IMPORTANCE OF VENTRICULAR ARRHYTHMIAS} IN HEART FAILURE

Many studies have shown that arrhythmias are indicators of a poor prognosis in heart failure 246 and several studies have also suggested that sudden death is the most common outcome. ${ }^{46}$ It remains to be proved that arrhythmias are indeed the cause of death, that these are sustained ventricular arrhythmias, and that they can be modified and death prevented by antiarrhythmic agents. Ambulatory electrocardiographic recordings obtained at the time of fatal cardiac arrests suggest that in about $75 \%$ of cases this is preceded by a sustained ventricular arrhythmia. ${ }^{36}$ Some researchers have related the frequency of these arrhythmias to the extent of left ventricular dysfunction ${ }^{37} 38$ and have suggested that, in dictating prognosis, the arrhythmias observed are of secondary importance to the haemodynamic state. Increased sympathetic activity, ${ }^{39}$ hypokalaemia, ${ }^{40}$ treatment with digoxin, ${ }^{41}$ and myocardial cell abnormalities may also contribute to arrhythmias. The relatively poorer prognosis of heart failure caused by coronary artery disease compared with that caused by dilated cardiomyopathy ${ }^{2}$ may also suggest that focal myocardial ischaemia is important in the aetiology of arrhythmias; however, subendocardial ischaemia, due to increased myocardial wall tension, can occur in any form of heart failure. Amiodarone has well documented coronary vaso- dilator actions and these may help to reduce arrhythmias indirectly by improving myocardial perfusion. The suggestion that sympathetic inhibition has a beneficial effect on left ventricular function must remain speculative in view of the controversy over whether $\beta$ adrenergic receptor blockade is helpful in heart failure. ${ }^{4243}$

According to the Framingham study $4 \%$ of the population under the age of 75 will develop heart failure before death ${ }^{44}$ In Britain this would account for 60000 new cases of heart failure per year. In Scotland alone there were over 6000 deaths in 1983 in which heart failure was a contributory cause (personal communication, Registrar General, New Registrar House, Edinburgh, Scotland). Though cardiac transplantation may be the most successful treatment for very poor left ventricular function, the problem is so large that transplantation is excluded in most patients. Patients with lesser degrees of heart failure also have a high annual mortality and alternative medical treatment is required to improve not only their symptoms but also their prognosis.

\section{EFFECTS OF TREATMENT}

The effect of an antiarrhythmic agent on the prognosis in heart failure has been investigated in another controlled trial. ${ }^{11}$ In that study procainamide did not improve prognosis; however, the groups were not randomly allocated to treatment and the efficacy of arrhythmia suppression was not commented on. We are unaware of any previous study that has investigated concurrently the long term haemodynamic and electrophysiological effects of antiarrhythmic drugs in heart failure. Some antiarrhythmic drugs such as disopyramide and flecainide seem to be unsuitable for use in heart failure because of their negative inotropic action. ${ }^{78}$ As agents such as $\beta$ blockers and verapamil have negative inotropic effects, they too seem less attractive; however, there are reports of a beneficial effect of $\beta$ blockers in heart failure. ${ }^{4243}$

\section{SIDE EFFECTS}

Because amiodarone has a long half life the dose may require careful titration and the regimen may have to be altered even after long term treatment. Arrhythmias can become worse in patients on amiodarone, ${ }^{45}$ often with the first few doses; this is possibly a consequence of its class I activity. ${ }^{46}$ Therefore, careful patient monitoring is required initially. We have encountered patients who are intolerant of $200 \mathrm{mg} /$ day because of gastrointestinal side effects and rhythm disturbances; some require $\leqslant 100 \mathrm{mg} /$ day to control their arrhythmias. One patient in this study developed much more frequent arrhythmias on the loading dose of $600 \mathrm{mg} /$ day but 
after withdrawal from the study he improved on a dose of $200 \mathrm{mg} /$ day. In another patient in this trial conduction disturbances developed at a dose of $200 \mathrm{mg} /$ day when the serum concentration of amiodarone was only $0.5 \mathrm{mg} / \mathrm{l}$. Patients with heart failure may be more sensitive to the effects of amiodarone. Left bundle branch block does not seem to be a contraindication to treatment, however, and this is confirmed by the experience of others. ${ }^{47}$

After three months' treatment with amiodarone we noted a significant fall in serum triiodothyronine and rise in thyroid stimulating hormone, implying a mildly hypothyroid state. None the less, no patient developed clinical signs of hypothyroidism, which accords with the small increase in the concentration of thyroid stimulating hormone. The assay for thyroid stimulating hormone is insensitive at low concentrations, however, and this result should be interpreted with caution. We found no clinical or biochemical evidence of hyperthyroidism in this study. The mechanism by which amiodarone blocks the conversion of thyroxine to triiodothyronine has been reviewed elsewhere. ${ }^{48}$ Tests of pulmonary function were unaffected by amiodarone, perhaps because the duration of treatment was short. ${ }^{49}$ One patient developed symptoms suggestive of peripheral neuropathy on $200 \mathrm{mg} /$ day. After the study he continued to take amiodarone $100 \mathrm{mg} /$ day with resolution of symptoms and continuing arrhythmia control. These and other side effects of amiodarone have been well reviewed by Harris et al and McKenna et al. 5051

In conclusion, amiodarone seems to be an effective treatment for arrhythmias in heart failure and does not worsen symptoms or exercise tolerance. Its use in conjunction with captopril appears to be safe. Occasional patients may have worsening of their arrhythmias after amiodarone; this appears early after its introduction and close supervision is recommended to prevent adverse reactions.

We thank Dr David Holt of the Poison's Unit, Guy's Hospital, London for measuring the plasma concentrations of amiodarone and $\mathrm{Dr} \mathrm{J} J$ Morton of the Medical Research Council Blood Pressure Unit, Glasgow for measuring plasma concentrations of angiotensin II and vasopressin. We also thank Esther Henderson for her diligence in helping to complete this study and the typescript. JGFC was supported by a Medical Research Council Training Fellowship during this study.

\section{References}

1 Meinertz T, Hofmann T, Kasper W, et al Significance of ventricular arrhythmias in idiopathic dilated cardiomyopathy. Am J Cardiol 1984;53:902-7.
2 Franciosa JA, Wilen M, Ziesche S, Cohn JN. Survival ฏ in men with severe chronic left ventricular failure $c$ due to either coronary artery disease or idiopathic dilated cardiomyopathy. Am J Cardiol 1983;51: $\stackrel{5}{\rightarrow}$ 831-6.

3 Cohn JN, Levine TB, Olivari MT, et al. Plasma norepinephrine as a guide to prognosis in patients with chronic congestive heart failure. $N \mathrm{Engl} J$ Med 1984;311:819-23.

4 Unverferth DV, Magorien RD, Moeschberger ML, ڤ Baker PB, Fetters JK, Leier CV. Factors influencing $\overrightarrow{0}$ the one-year mortality of dilated cardiomyopathy. Am J Cardiol 1984;54:147-52.

5 McKenna WJ, Krikler DM, Goodwin JF. Arrhythmias in dilated and hypertrophic cardiomyopathy. Med Clin North Am 1984;68:983-1000.

6 Holmes J, Kubo SH, Cody RJ, Kligfield P. Arrhyth- ir mias in ischemic and nonischemic dilated cardio- is myopathy: prediction of mortality by ambulatory electrocardiography. Am J Cardiol 1985;55:146-51.

7 Josephson MA, Kaul S, Hopkins J, et al. Hemodynamic effects of intravenous flecainide relative to the level of left ventricular function in patients with coronary artery disease. Am Heart J 1985;109:41-5.

8 Sutton R. Haemodynamics of intravenous disopyramide. J Int Med Res 1976;4(suppl 1):46-8.

9 Ferlinz J, Easthope JL, Aronow WS. Effects of verapamil on myocardial performance in coronary artery disease. Circulation 1979;59:313-9.

10 Robinson C. Haemodynamic effects of atenolol in patients with coronary artery disease. Br Heart $J$ 1978;40:22-8.

11 Chakko CS, Gheorghiade $M$. Ventricular arrhythmias in severe heart failure: incidence, significance, and effectiveness of antiarrhythmic therapy. Am Heart $J$ 1985;109:497-504.

12 Singh BN, Vaughan-Williams EM. The effects of amiodarone, a new anti-anginal agent drug of cardiac muscle. Br J Pharmacol 1970;39:657-67.

13 Côté P, Bourassa MG, Delaye J, Janin A, Froment R, David P. Effects of amiodarone on cardiac and coro- 3 nary hemodynamics and on myocardial metabolism in patients with coronary artery disease. Circulation 1979;59:1165-72.

14 Singh BN, Jewitt DE, Downey JM, Kirk ES, O Sonnenblick EH. Effects of amiodarone and L8040, $\frac{D}{O}$ novel antianginal and antiarrhythmic drugs, on cardiac and coronary hemodynamics and on cardiac $N$ intracellular potentials. Clin Exp Pharmacol Physiol 1976;3:427-42.

15 Pfisterer M, Burkart F, Muller-Brand J, Kiowski W. స Important differences between short- and long-term $\sigma$ effects of amiodarone in patients with chronic ischemic heart disease at rest and during ischemiainduced left ventricular dysfunction. J Am Coll Car- \& diol 1985;5:1205-11.

16 Schwartz A, Shen E, Morady F, Gillespie K, Schienman $M$, Chatteriee $K$. Hemodynamic effects of intra- $\frac{O}{\mathbb{D}}$ venous amiodarone in patients with depressed left $\stackrel{\mathcal{Q}}{\Phi}$ ventricular function and recurrent ventricular tachy- $\unrhd$ cardia. Am Heart J 1983;106:848-55.

17 Millar JA, Leckie BJ, Semple PF, Morton JJ, Sonkodi 
$S$, Robertson JIS. Active and inactive renin in human plasma: renal arteriovenous differences and relationship with angiotensin and renin substrates. Circ Res 1978;43(suppl 1):120-7.

18 Atkinson AB, Morton JJ, Brown JJ, et al. Captopril in clinical hypertension. Changes in components of renin-angiotensin system and in body composition in relation to fall in blood pressure with a note on measurement of angiotensin II during converting enzyme inhibition. Br Heart J 1980;44:290-6.

19 Fraser R, Guest S, Young J. Comparison of double isotope derivative and radio-immunological estimation of plasma aldosterone concentration. Clin Sci Mol Med 1973;45:411-5.

20 Ball SG, Tree M, Morton JJ, Inglis GC, Fraser R. Circulating dopamine: its effect on the plasma concentrations of catecholamines, renin, angiotensin, aldosterone and vasopressin in the conscious dog. Clin Sci 1981;61:417-22.

21 Charlier R. Cardiac actions in the dog of a new antagonist of adrenergic excitation which does not produce competitive blockade of adrenoreceptors. $\mathrm{Br} J$ Pharmacol 1970;39:668-74.

22 Finermann WB, Hamer A, Peter T, Weiss D, Mandel WJ. Electrophysiologic effects of chronic amiodarone therapy in patients with ventricular arrhythmias. $\mathrm{Am}$ Heart $J$ 1982;104:987-96.

23 Wellens HJJ, Brugada P, Roy D, Heddle B, Bar FW. A comparison of the electrophysiological effects of intravenous and oral amiodarone [Abstract]. $\mathrm{Am} \mathrm{J}$ Cardiol 1982;49:1043.

24 Sharma AD, Corr PB. Modulation by amiodarone of cardiac adrenergic receptors and their electrophysiologic responsivity to catecholamines [Abstract]. Circulation 1983;68(suppl III):99.

25 Gagnol JP, Devos C, Clinet M, Nokin P. Amiodarone: biochemical aspects and haemodynamic effects. Drugs 1985;29(suppl 3):1-10.

26 Bellotti G, Silva LA, Filho AE, et al. Haemodynamic effects of intravenous administration of amiodarone in congestive heart failure from chronic Chagas' disease. Am J Cardiol 1983;52:1046-9.

27 Greene HL, Graham EL, Werner JA, et al. Toxic and therapeutic effects of amiodarone in the treatment of cardiac arrhythmias. J Am Coll Cardiol 1983;2: 1114-28.

28 Trobaugh GB, Kudenchuk PJ, Green HL, et al. Effect of amiodarone on ventricular function as measured by gated radionuclide angiography. Am J Cardiol 1984;54:1263-6.

29 Ellenbogen KA, O'Callaghan WG, Colavita PG, Smith MS, German LD. Cardiac function in patients on chronic amiodarone therapy. Am Heart J 1985;110:376-81.

30 Debbas NMG, du Cailar C, Sassine A, Derancourt J, Demaille JG, Puech P. Determination of cardiac and plasma drug levels during long-term amiodarone therapy. Eur J Clin Invest 1983;13:123-7.

31 Debbas NMG, du Cailar C, Bexton RS, Demaille JG, Camm AJ, Puech P. The QT interval: a predictor of the plasma and myocardial concentration of amiodarone. Br Heart J 1984;51:316-20.

32 Holt DW, Tucker GT, Jackson PR, Storey GCA. Amiodarone pharmacokinetics. Am Heart J 1983; 106:840-7.
33 Moysey JO, Jaggarao NSV, Grundy EN, Chamberlain DA. Amiodarone increases plasma digoxin concentrations. Br Med J 1981;282:272.

34 Maheswaran R, Bramble MG, Hardisty CA. Massive digoxin overdose: successful treatment with intravenous amiodarone. $\mathrm{Br} \mathrm{Med} J$ 1983;287:392-3.

35 Cleland JGF, Dargie HJ, Pettigrew A, Gillen G, Robertson JIS. The effect of captopril on serum digoxin and urinary digoxin clearance in patients with heart failure. Am Heart $J$ 1986;112:130-5.

36 Milner PG, Platia EV, Reid PR, Griffith LSC. Ambulatory electrocardiographic recordings at the time of fatal cardiac arrest. Am J Cardiol 1985;56:588-92.

37 Diaz R, Obasohan A, Newman H, Goodwin JF, Oakley C. Prognostic indicators in dilated cardiomyopathy [Abstract]. Br Heart J 1985;53:114.

38 von Olshausen K, Schäfer A, Mehmel HC, Schwarz F, Senges J, Kübler W. Ventricular arrhythmias in idiopathic dilated cardiomyopathy. $\mathrm{Br}$ Heart $J$ 1984; 51:195-201.

39 Reddy CP, Gettes LS. Use of isoproterenol as an aid to electrical induction of chronic recurrent ventricular tachycardia. Am J Cardiol 1979;44:705-13.

40 Hollifield JW, Slaton PE, Moore LC. Diuretic treatment of hypertension: hypokalaemia and cardiac arrhythmias complicating thiazide therapy. International Medicine 1983;5(suppl):127-31.

41 Shapiro W. Corrective studies of serum digitalis levels and the arrhythmias of digitalis intoxication. $\mathrm{Am} \mathrm{J}$ Cardiol 1978;41:852-9.

42 Waagstein F, Hjalmarson $\AA$, Varnauskas E, Wallentin I. Effect of chronic beta-adrenergic receptor blockade in congestive cardiomyopathy. $\mathrm{Br}$ Heart $\mathrm{J}$ 1975;37:1022-36.

43 Taylor SH, Silke B. Haemodynamic effects of betablockade in ischaemic heart failure. Lancet 1981; ii:835-7.

44 McKee PA, Castelli WP, McNamara PM, Kannel WB. The natural history of congestive heart failure: the Framingham study. $N$ Engl J Med 1971;285:1441-6.

45 Sclarovsky S, Lewin RF, Kracoff O, Strasberg B, Arditti A, Agmon J. Amiodarone-induced polymorphous ventricular tachycardia. Am Heart $J$ 1983;105:6-12.

46 Cobbe SM, Manley BS. Cellular electrophysiology of amiodarone in cardiac ischaemia. $\mathrm{Br} \mathrm{J} \mathrm{Clin} \mathrm{Pract}$ 1986;40:104-6.

47 Kaski JC, Girrotti LA, Messuti .H, Rutitzky B, Rosenbaum MB. Long-term management of sustained, recurrent, symptomatic ventricular tachycardia with amiodarone. Circulation 1981;64:273-9.

48 Sanmarti A, Permanyer-Miralda G, Castellanos JM, Foz-Sala M, Galard RM, Soler-Soler J. Chronic administration of amiodarone and thyroid function: a follow up study. Am Heart J 1984;108:1262-8.

49 Kudenchuk PJ, Pierson DJ, Greene HL, Graham EL, Sears GK, Trobaugh GB. Prospective evaluation of amiodarone pulmonary toxicity. Chest 1984;86: 541-4.

50 Harris L, McKenna WJ, Rowland E, et al. Side effects of long-term amiodarone therapy. Circulation 1983; 67:45-51.

51 McKenna WJ, Rowland E, Krikler DM. Amiodarone: the experience of the past decade. $\mathrm{Br}$ Med $J$ 1983;287:1654-6. 